\title{
A Call for Diabetes Self-management Education
}

\author{
Linda Siminerio, RN, PhD, CDE \\ Professor of Medicine, Executive Director, University of Pittsburgh Diabetes Institute, Pittsburgh, Pennsylvania, uS
}

\begin{abstract}
Summary
It is widely accepted that diabetes self-management education (DSME) is an important component of care. It has been shown that DSME is associated with improvements in clinical, behavioral, and psychosocial outcomes. Despite proven benefits, the number of patients who receive DSME are disappointingly small. Introducing educator services in primary care has been shown to improve access and outcomes. As the diabetes epidemic continues, strategies to help patients meet targets and lower risk for complications are needed. The provision of DSME is critical in overcoming barriers to good-quality care. Those responsible for delivering good quality care need to mobilize efforts and explore avenues to meet the needs of those living with complex chronic diseases.
\end{abstract}

\section{Keywords}

Self-management, education, diabetes

Disclosure: Linda Siminerio, RN, PhD, CDE, has no conflicts of interest to declare. No funding was received for the publication of this article open Access: This article is published under the Creative Commons Attribution Noncommercial License, which permits any noncommercial use, distribution, adaptation, and reproduction provided the original author(s) and source are given appropriate credit. Received: February 25, 2015 Accepted: March 16, 2015 Citation: US Endocrinology, 2015;11(1):28-9 DOI: http://doi.org/10.17925/USE.2015.11.1.28 Correspondence: Linda Siminerio, RN, PhD, CDE, University of Pittsburgh Diabetes Institute, Falk Medical Building, Room 562, 3601 Fifth Avenue, Pittsburgh PA 15213, US. E: simineriol@upmc.edu

It is widely accepted that diabetes self-management education (DSME) (and ongoing support) is an important component of care. ${ }^{1}$ Diabetes is a lifestyle disease that requires that the person living with the disease to make numerous daily decisions regarding food, activity, and medications. It also requires that the person be proficient in a number of self-care skills, such as blood glucose monitoring, foot exams, and self-administering medications. ${ }^{2}$ DSME is critical in laying the foundation for people to learn how to be effective self-managers. Diabetes educators, who are likely nurses, dietitians, or pharmacists, are trained in the skills necessary to support behavior change, and they provide direct assistance to help patients self-manage.

It has repeatedly been demonstrated that diabetes educators can improve the gold standard of diabetes clinical outcomes: A1C levels. Studies have shown as much as a $0.76 \%$ reduction in $\mathrm{A} 1 \mathrm{C}$ levels immediately after DSME is delivered. Because a $1 \%$ decrease in A1C is associated with a dramatic reduction in myocardial infarctions, microvascular disease, and death, a $0.76 \%$ reduction can be considered an enormous benefit. The effect of DSME on A1C levels has been directly correlated to the amount of contact time spent between educator and patient. Contact time with an educator was the only significant predictor of reduction in $\mathrm{A} 1 \mathrm{C}-23.6$ hours needed for every $1 \%$ absolute decrease in $\mathrm{A} 1 \mathrm{C} .^{3}$ The take-home message? The more time a patient has with an educator, the better. Diabetes education has also been shown to be associated with significant improvements on behavioral and psychosocial outcomes, such as adherence, empowerment, and quality of life..$^{4-6}$
Despite the proven benefits, the numbers of patients who receive diabetes educator services are disappointingly small. ${ }^{7}$ In a recent report, an estimated $6.8 \%$ of privately insured, newly diagnosed adults participated in DSME during the first year after diagnosis of diabetes. ${ }^{8}$ Only $4 \%$ of all Medicare enrollees who have diagnosed diabetes participate in DSME and medical nutrition therapy (MNT) services. ${ }^{9}$ These data suggest that there is a large gap between recommended guidelines and current practice, as well as that there is both the opportunity and the need to enhance rates of DSME participation.

Access to education has been proposed as a potential barrier, particularly in rural and underserved communities, where the closest DSME program may be miles away. ${ }^{10}$ Another problem may be how education has traditionally been prescribed and delivered. Currently, physicians are expected to refer diabetes patients to a hospital-based DSME program, but lack of physician referrals has been reported as a major barrier. Patients also face many challenges following through on referrals, including because of lack of understanding of the need of the service, distance, scheduling constraints, cultural and language challenges, and reluctance to attend a program in a hospital setting. ${ }^{11}$

In a meta-analysis of diabetes quality-improvement efforts, efforts that addressed team changes and system redesign showed more robust improvements in glycemia than did any other strategy. ${ }^{12}$ The unique skill sets that a team brings have been supported in the literature. ${ }^{13}$ For example, in the global Diabetes Attitude Wishes and Needs (DAWN) 
study, patients who had access to diabetes team members, such as nurses, were reported to have better outcomes. ${ }^{14}$

Several programs have demonstrated positive outcomes in facilitating self-management education and team care in community settings. Introducing educator services in primary care has been shown to improve access and process and patient outcomes. ${ }^{15-19}$ By reorganizing practice to facilitate self-management education within the practice, educators have been able to provide education and support for patients newly diagnosed or undergoing regimen changes and advanced pharmacotherapy. Studies have shown that when educators are added to primary care settings, patients are better able to self-manage and meet treatment goals. ${ }^{16,19}$

As the diabetes epidemic continues, more strategies to help patients meet their targets and lower their risk of diabetes complications are needed. The provision of team care and DSME is critical in overcoming the barriers associated with the skills and complexities of diabetes care. Challenges such as poor access, poor reimbursement, limited training in psychological management, and limited time with patients must be overcome.

Healthcare decision-makers and providers responsible for delivering good-quality diabetes care need to mobilize efforts and explore new avenues to meet the needs of people living with complex chronic diseases. Opportunities to partner with primary care providers to provide education in their practices; consideration of patient incentives, such as by waiving copayments; revisiting reimbursement models for team members; and technological approaches for the creation of virtual teams must all be investigated and supported. But most of all, educators and physicians must be open minded when considering areas for change. Those responsible for delivering good quality diabetes care must mobilize efforts and explore new avenues to meet the needs of those living with complex chronic diseases, such as diabetes.
1. American Medical Association (AMA) and National Committee for Quality Assurance (NCQA), Adult diabetes: performance measures, AMA-convened Physician Consortium for Performance Improvement, 2014. Available at: www.amaassn.org/apps/listserv/x-check/qmeasure.cgi?submit=PCPI (accessed March 1, 2015)

2. Peeples M, Tomky D, Mulcahy K, et al., Evolution of the American Association of Diabetes Educators' Diabetes Education Association of Diabetes Educators Diabetes Education

3. Norris S, Engelgau M, Narayan K, Effectiveness of selfmanagement training type 2 diabetes: a systematic review of randomized controlled trials, Diabetes Care, 2001;24:561-87.

4. Gary TL, Genkinger JM, Guallar E, et al., Meta-analysis of randomized educational and behavioral interventions in type 2 diabetes, Diabetes Educ, 2003;29:488-501.

5. Jack L, Diabetes self-management education research: an international review of intervention methods, theories, community partnerships and outcomes, Dis Manag Health Out, 2003;11:415-28.

6. Siminerio L, Ruppert K, Huber K, et al., Telemedicine for Reach, Education, Access and Treatment (TREAT): linking telemedicine with diabetes self-management education to improve care in rural communities, Diabetes Educ, 2014:40:797-805.
7. CDC, Age-Adjusted Percentage of Adults Aged 18 Years or Older with Diagnosed Diabetes Ever Attending a Diabetes Self-Management Class, United States, 2000-2010, Atlanta, GA: US Department of Health and Human Services; 2014. Available at: www.cdc.gov/diabetes/statistics/preventive/fy_class.htm (accessed April 20, 2015)

8. Rui L, Shrestha S, Lipman R, et al., Diabetes self-management education and training among privately insured persons with newly diagnosed diabetes_-United States, 2011-2012, MMWR 2014:63:1046-9.

9. Duncan I, Birkmeyer C, Coughlin S, et al., Assessing the value of diabetes education, Diabetes Educ, 2009;35:752-60.

10. Siminerio L, Piatt G, Zgibor J, Implementing the chronic care model in a rural practice, Diabetes Educ, 2005;31:225-34.

11. Peyrot $M$, Rubin $R$, Funnell $M$, et al., Access to diabetes selfmanagement education: results of national surveys of patients, educators and physicians, Diabetes Educ, 2009:35:24.

12. Shojania KG, Ranji SR, McDonald KM, et al., Effects of quality improvement strategies for type 2 diabetes on glycemic contro JAMA, 2006;296:427-40.

13. Funnell MM, Peyrot MF, Rubin RR, Siminerio LM. Steering toward a new DAWN in diabetes management: using diabetes nurse educators in primary care for patient empowerment, psychological support, and improved outcomes, Diabetes Educ, 2005:(Suppl. 31):1-18.

14. Rubin R, Peyrot M, Siminerio L, Health care and patient-reported outcomes: results of the cross-national Diabetes Attitudes, Wishes and Needs (DAWN) study, Diabetes Care, 2006;29:1249-55

15. Siminerio L, Ruppert K, Gabbay R, Who best provides diabetes self-management support in primary care? Findings from a randomized controlled trial Diabetes Educ, 2013:39:705-13.

16. Siminerio L, Ruppert $K$, Emerson $S$, et al., Delivering diabetes self-management education (DSME) in primary care, Dis Manag Health Out, 2008;16:267-72.

17. Ridgeway N, Harvill D, Harvill L, et al., Improved control of type 2 diabetes mellitus: a practical education/behavior modification program in a primary care clinic, South Med $\rfloor_{4}$ 1999:92:667-72.

18. Piatt G, Songer T, Brooks M, et al., Impact of patient level factors on the improvement of the ABCs of diabetes, Patient Educ Couns, 2011;82:266-70.

19. Piatt $G$, Anderson $R$, Brooks $M$, et al., 3-year follow-up of clinical and behavioral improvements following a multifaceted diabetes care intervention: results of a randomized controlled trial. Diabetes Educ, 2010;36:301-9. 